\section{Need to intensify emergency obstetric care services in Nigeria}

\section{Perpetus C. Ibekwe \\ Department of Obstetrics \& Gynaecology, Ebonyi State University Teaching Hospital, Abakaliki, Nigeria}

Each year more than half a million women around the world die from complications of pregnancy and childbirth; this number has not declined substantially in over two decades. ${ }^{1}$ Ninety-nine percent of these deaths occur in the developing world; Africa and Asia together accounting for $95 \%$ of the maternal deaths. ${ }^{2}$ The life time risk of maternal death in subSaharan Africa is one in 16, while the risk in developed countries is one in $2800 .^{3}$

In Nigeria, since the launching of the Safe Motherhood Initiative (SMI) in September 1990, overwhelming evidence suggests a trend towards an increasing rate of maternal mortality. Available data indicate that Nigeria now has the second highest rate of maternal mortality in the developing world. ${ }^{4}$ Officially, the maternal mortality rate (MMR) is estimated at 800 maternal deaths per 100,000 live births. ${ }^{5}$ However, institutional figures on MMRs are staggering and frightening -2101 per $100,000^{6}$ and 3380 per $100,000^{7}$ from two centres in Nigeria. Whereas Nigeria makes up $2 \%$ of the world's population, it contributes about $10 \%$ of the global burden of maternal deaths. ${ }^{8}$ These deaths are unacceptably high even by African standard.

The three-delay model explains the risks a woman faces in pregnancy which invariably are determinants of maternal mortality and morbidity. The first delay explains the delay in the recognition of warning signs and in the decision to seek care. A second delay is caused by barriers of distance and transportation that is the time needed to arrive at the appropriate facility, which is a function of distance and availability of transportation. A third delay occurs in receiving care at the facility probably due to lack of provision or access to emergency obstetric care (EmOC).

On the other hand, prevention of maternal mortality depends on intervention at the 3 levels of prevention strategies: primary, secondary and tertiary prevention. Primary prevention involves the reduction in un-timed and unwanted pregnancies that place women at risk of death. Secondary prevention emphasises antenatal care as an essential component in the fight against maternal mortality. This detects potential problems that may lead to pregnancy complications and resolves them before they become late. It has been shown and is now increasingly becoming evident that tertiary prevention, the prompt treatment of complications that lead to maternal death, holds the key to the reduction of maternal mortality in developing countries. ${ }^{9}$ This obviously lies in the provision of EmOC.

EmOC refers to the care of women and newborn during pregnancy, delivery and the time after delivery. It specifically ensures timely access to care of women experiencing complications. EmOC has two components - Basic and Comprehensive Em0C. Basic Em0C include:

- Treatment of sepsis through provision of potent parenteral antibiotics;

- Treatment of eclampsia through provision of parenteral anticonvulsant;

Treatment of prolonged or obstructed labour,

- Post abortion Care (PAC),

Treatment for incomplete abortion;

Manual removal of placenta;

- Assisted delivery using forceps or suction.

Comprehensive Em0C services include those listed above, and also:

Surgery (specifically caesarean section);

Anaesthesia;

Safe blood transfusion.

Basic Em0C can be provided in health centers, while comprehensive EmOC must be provided in facilities at the hospital level.

Globally, $75 \%$ of all maternal deaths are due to five causes, all of which can be treated. ${ }^{10}$ These causes are haemorrhage, obstructed labour, sepsis, eclampsia and unsafe abortion. These are $100 \%$ preventable through improved access to adequate health-care services and EmOC. Thus, if adequate and timely EmOC is provided, most maternal deaths can be prevented, ${ }^{11}$ and WHO Safe Motherhood programme in 1987 emphasised the importance of access to EmOC if maternal mortality reduction is to progress. ${ }^{12,13}$

According to the UN recommendations (1997), there should be at least one comprehensive and four basic EmOC facilities per 500,000 population. ${ }^{14}$ If this is properly analysed, it will be seen that the facilities in Nigeria and indeed most developing countries are far cry from the minimum UN recommendations. Studies in other countries have found that comprehensive EmOC facilities, but not basic EmOC facilities, tend to be numerically adequate in relation to population. ${ }^{15,16}$

Even as sparsely as these facilities are distributed in Nigeria, there are palpable inadequacies at the level of the service delivery points - hospitals, health centres and maternities which lead to undue delays in the handling of pregnancy complications and therefore hinder prompt access to EmOC to women in dire need of attention. In most health institutions, facilities for EmOC are virtually non-existent. Oxytocics, anticonvulsants, potent antibiotics, safe anaesthesia, ambulance and blood trans-
Correspondence: Dr. Perpetus Chudi Ibekwe, Department of Obstetrics \& Gynaecology, Ebonyi State University Teaching Hospital, P0 Box 1019, Abakaliki 480001, Ebonyi State, Nigeria.

E-mail: drogoperps@yahoo.com

Key words: maternal mortality, reduction, emergency obstetric care, provision, developing countries.

Conflict of interest: the authors report no conflicts of interest.

Received for publication: 7 September 2011. Accepted for publication: 23 June 2011.

This work is licensed under a Creative Commons Attribution NonCommercial 3.0 License (CC BYNC 3.0).

(C) Copyright P.C. Ibekwe, 2011

Licensee PAGEPress, Italy

Journal of Public Health in Africa 2011; 2:e33

doi:10.4081/jphia.2011.e33

fusion services are either not available or ill equipped. Also, requisite manpower to administer anaesthesia, perform caesarean section or conduct instrumental delivery are non available when required. Decision-intervention interval, which should not exceed 30 minutes, often runs into hours or days.

From the foregoing, there is urgent need for a concerted effort on the part of individuals, communities, government and partners interested in improving women's health towards putting in place workable structures at our healthcare facilities to curb maternal deaths. In the first place, health systems should be strengthened with both human and material resources to make them optimal. The availability of skilled health providers is critical in attaining the objectives of the Em0C. Indeed, the MDG-5 is unlikely to be achieved without attention to the recruitment and retention of health professional. ${ }^{17}$ Their services should be made accessible and affordable and should be equitably distributed in both rural and urban centres. Incentives should be given to skilled personnel to attract them to rural areas where their services are most needed.

Secondly, for EmOC to be effective, basic EmOC must be linked to community services, and an efficient referral system must be in place so that woman who needed comprehensive EmOC can access it in a timely manner. Weak referral systems, especially during obstetric emergencies, contribute significantly to delays in reaching health facilities for prompt and appropriate care. ${ }^{18}$ In our environment referral systems are haphazard, uncoordinated and chaotic. An efficient and effective referral system must include feedback to the original referral point or health professional in 
order to foster an ethos of reflective practice and for strengthening continuity and quality of care.

The ultimate challenge is to ensure the availability $24 / 7$ of basic and comprehensive Em0C services geographically distributed to maximize access for the greatest number of women, especially in rural areas. This can begin by improving and upgrading facilities, improving staffing, enhancing skills through training, improving management and supervision, ensuring availability of supplies and keeping proper records. This will aim at meeting the UN minimum recommendation for EmOC services.

Finally, steps must be taken to develop the peoples' confidence in the quality of available services and through community education create awareness of obstetric complications and maternal mortality issues.

\section{References}

1. UNICEF. Maternal Health. 2007 Available from: http://www.unicef.org/health/index maternal health.html

2. UNFPA. Reproductive Health Fact Sheet. New York, USA 2005. Available from: http://www.unfpa.org/swp/2005/presskit/fa ctsheets/facts_rh.htm

3. UNICEF, UNFPA and WHO. Maternal Mortality in 2000. Estimates developed by
WHO, UNICEF and UNFPA. Geneva, Switzerland, 2004.

4. Friday Okonofua. Need to intensify Safe Motherhood Interventions in Africa. Afr J Reprod Health 2003;7:7-9.

5. Population Reference Bureau. 2006 World population data sheet. Available from: http://www.prb.org/pdf06/06worlddatasheet.pdf

6. Malah GS, El-Nafaty AU, Audu Bm, Kizaya D. Maternal Mortality at the Specialist Hospital Gombe, Nigeria. Analysis of the determinant factors in obstetric tropic practice. Proc. 34th Scientific Conf. Society Obstetrics and Gynaecology of Nigeria (SOGON), November 22-25, 2000.

7. Ibekwe PC, Dimejesi IB. Obstetric Indices at the Ebonyi State University Teaching Hospital, Abakaliki, Nigeria. Niger J Med 2008;17:399-402.

8. Federal Ministry of Health. Road map for accelerating the attainment of the MDGs related to maternal and newborn health in Nigeria. FMOH, Nigeria, 2005.

9. Benagiano G, Thomas B, International Federation of Gynecology and Obstetrics. Safe motherhood: The FIGO initiative. Int J Gynecol Obstet 2003;83:263-74.

10. World Health Organisation. Managing complications in Pregnancy and childbirth: a guide for midwives and doctors. Geneva, Switzerland, 2000. Available from: http://www.who.int/making_pregnancy_sa fer/survey/en/index.html
11. Thaddeus S, Maine D. Too far to walk: Maternal Mortality in context. Soc Sci Med 1994; 38: 1091-110.

12. Maine D, Rosenfield A. The Safe motherhood initiative: Why has it stalled. Am J Public Health 1999; 89: 480-482.

13. World Health organisation. Mother-baby package: a roadmap for implementation in countries. Geneva, Switzerland, Division of Family Health, 1994.

14. Maine D, Wardlaw TM, Ward VM, et al. Guildlines for monitoring the availability and use of obstetric services. UNICEF/ WHO/UNFPA, New York, NY, USA 1997. Available from: http://www.childinfo.org/ files/maternal_mortality_finalgui.pdf

15. Bailey P, Paxton A. Program Note: using UN Process indicators to assess needs in emergency obstetric services (Mozambique, Nepal and Senegal). Int J Gynecol Obstet 2002;76:299-305.

16. Paxton A, Bailey P, lobis S, Fry D. Global Patterns in availability of emergency obstetric care. Int J Gynecol Obstet 2006; 93:300-7.

17. Wyss K. An approach to classifying human resources constraints to attaining healthrelated Millennium. Development Goals. Hum Resour Health 2002;2:94-8.

18. Ibekwe PC, Ibekwe RO. Provision of Essential Obstetric Care (EOC): a sine qua non to reducing maternal mortality in Nigeria. Promot Educ 2008;15:50-52. 